\title{
Moral injury in a context of trauma
}

Edgar Jones

\begin{abstract}
Summary
Moral injury, characterised by guilt, shame and self-condemnation, is conceptualised either as an adjunct to post-traumatic stress disorder or as a new syndrome. Studies of symptoms and potentially morally injurious events have produced a possible definition and informed the design of rating scales. The current challenge remains the design of effective interventions. Because moral injury relates to ethical behaviour, the meaning attached to events and perceptions of the self, moral philosophy and spirituality could contribute to the design of treatments.
\end{abstract}

\section{Declaration of interest}

None.

\section{Keywords}

Moral injury; veterans; post-traumatic stress disorder; transgressive acts; post-traumatic illness.

\section{Copyright and usage}

(c) The Author 2020.
Edgar Jones is Professor of the History of Medicine and Psychiatry at the Institute of Psychiatry, Psychology and Neuroscience, King's College London, where he is also programme leader for the MSc course in War and Psychiatry. His research interests include the psychology of war and terrorism.

Moral injury is a term proposed to describe the distress that individuals feel when they perpetrate, witness or fail to prevent an act that transgresses their core ethical beliefs. Yet to be classified as a form of mental illness with an agreed definition, it has been described as a syndrome, characterised by guilt, shame, intrusive thoughts and self-condemnation. Moral injury shares some similarities with post-traumatic stress disorder (PTSD), notably in criterion $\mathrm{D}$, the affective domain, as defined by DSM-5. ${ }^{1}$ It differs from the classic ethical dilemma in which a person is forced to decide between two justifiable but mutually opposing actions. In such a case, the person retains the agency of choice but in moral injury individuals commonly feel at the mercy of events, constrained by an overarching strategy or hierarchical rules that govern their actions. For some, it may erode their sense of meaning and place in the world, even challenging their faith. Religious beliefs and spirituality have been correlated with post-traumatic growth and are inversely associated with symptoms of PTSD, suggesting that they could be important variables for moral injury.

\section{The development of the concept}

The link between mental illness and moral injury was explicitly drawn in the 1990s by Jonathan Shay, a psychiatrist at the Department of Veterans Affairs in Boston, Massachusetts, when attempting to explain the enduring nature of PTSD suffered by US veterans of the Vietnam War. However, the concept failed to capture the attention of clinicians and researchers working in the field of post-traumatic illness. The extended military campaigns in Iraq and Afghanistan proved to be the catalyst for its recognition. US veterans of these deployments had elevated rates of PTSD, depression and suicide. The sustained trauma of deployment to war zones and the challenge of civilian reintegration were identified as key causal factors. In contrast with the Second World War, when citizens were widely engaged in the conflict through conscription and the mobilisation of the economy, most Americans had little personal understanding of the challenges of combat. Although 2.6 million US soldiers deployed to Iraq and Afghanistan, less than $0.5 \%$ of the population served in the armed forces. Such a limited military footprint was thought to have created a cultural dissonance that allowed moral injury to develop, and by 2009 the concept had begun to gather momentum, inspiring a number of studies that explored its clinical expression. ${ }^{2}$ When a systematic review showed that $60-72 \%$ of US veterans treated for PTSD with cognitive processing therapy or prolonged exposure therapy continued to meet the criteria for PTSD after treatment, ${ }^{3}$ it was hypothesised that moral injury was either an element of post-traumatic illness that these treatments failed to address or a phenomenon that prevented them from working effectively.

\section{DSM-5 and ICD-11}

Changes to the criteria for PTSD introduced to DSM-5 in 2013 went some way to accommodating the concept of moral injury. The diagnosis was no longer predicated on a reaction characterised by fear, helplessness or horror, and the event itself could be directly involved, witnessed or experienced indirectly. As a result, groups that plausibly experience moral injury, such as emergency workers who encounter the traumatic consequences of a natural disaster or conflict and military drone operators who observe the effects of their missile strikes from positions of safety, now meet the entry criteria for PTSD. The revised symptom clusters (intrusion, avoidance, negative alterations in cognition and mood, and alterations in arousal and activity) provide for a wider range of responses that are more attuned to morally injurious events. These definitional changes prompt the question as to whether moral injury that arises in a context of trauma should be regarded as a variant of PTSD. If so, should the term moral injury be restricted to those cases where the individual feels shame and guilt without being exposed to the new criterion A, 'death, threatened death, actual or threatened serious injury, or actual or threatened sexual violence'?

The reason why moral injury itself was not included in DSM-5 or ICD- $11^{4}$ was lack of consensus about its nature and uncertainty about how to measure the syndrome in a clinical setting. The original definition proposed by Shay identified failures by leaders, leading to 'a betrayal of what's right, by someone who holds legitimate authority, in a high-stakes situation' (p. 183). ${ }^{5}$ A later definition, based on research with Iraq and Afghanistan war veterans, focused on an individual's perception of moral failure. This interpretation 
required a person to have experienced a potentially morally injurious event (PMIE), which in function is similar to criterion A in PTSD. ${ }^{2}$ Not everyone in a group exposed to a PMIE will develop moral injury, as the phenomenon arises from a significant dissonance with the individual's belief system and world-view. Although a traumatic event is regarded as the primary cause in PTSD, research may show that it occupies a secondary role in moral injury because the latter is driven by an evaluation of the self. To experience shame, a person has to feel that they have fallen short of a code of behaviour that they had set for themselves.

\section{Rating scales and PMIEs in mental illness}

There is currently no threshold for when an event meets the criteria for moral injury, in part because rating scales are still being evaluated. Two commonly used instruments are the 9-item Moral Injury Events Scale (MIES) and the 19-item Moral Injury Questionnaire - Military Version (MIQ-M), both of which assess events and symptoms. The 45-item Moral Injury Symptom Scale Military Version, Long Form (MISS-M-LF) is probably the most comprehensive, assessing ten dimensions of moral injury, including the psychological and spiritual aspects. However, a challenge with such measures is the need to avoid confounding an exposure to morally injurious experience, also known as a 'transgressive act', with an outcome, as in 'I saw things that were morally wrong. ${ }^{6}$ The problem arises because it is difficult to design a succinct range of events that would meet most ethical issues.

Although moral injury is not currently categorised as a form of mental illness, a systematic review of 13 studies, representing 6373 participants, found that PMIEs accounted for $9.4 \%$ of the variance in PTSD, $5.2 \%$ of the variance in depression and $2.0 \%$ of the variance in suicidality. ${ }^{7}$ However, nine of the investigations were of military populations, one was of police officers and one of journalists reporting on the terrorist attack by Anders Breivik. The small number of studies and the limited data available on civilian occupational groups led the authors to caution about the strength of the relationship between moral injury and mental disorders.

\section{Treatment}

In America, specific treatments have been developed (acceptance and commitment therapy and adaptive disclosure), and in the UK clinicians have reported using trauma-focused cognitive-behavioural therapy and compassion-focused therapy. A core requirement of any intervention is the need to reframe or recategorise the injurious event in a way that allows the individual a measure of equanimity on its recall. This can involve reparative activity, such as undertaking voluntary work for those who suffered as a consequence of the person's actions or gathering evidence about an event with unclear outcomes. Psychodynamic therapy may have a role in addressing guilt and shame through an exploration of the self, although typically it would not focus exclusively on the injurious event.

\section{Clinical value}

As well as holding the promise of new insights, moral injury presents a challenge for psychiatry. As a concept, it falls between ethics, philosophy of mind, epistemology and social psychology. As a result, the clinical interpretation of moral injury runs the risk of medicalising ethical behaviour when associated with distress, or pathologising the emotions that arise when a person is presented with a complex or irreconcilable dilemma. In certain circumstances, shame and guilt may be appropriate and have a positive function if they lead to insight and changed behaviour.

In the context of this themed issue on disasters and trauma, the key question remains, what value would a diagnostic variant of moral injury hold for clinicians? If it adds a missing or complementary element to PTSD and results in supplementary treatments, then it will have proved its worth. Although a consensus is forming around a definition and a number of rating scales have been proposed to measure both injurious events and symptoms, the current challenge is the design of effective interventions. As moral injury does not fall within the exclusive territory of the psychiatrist or clinical psychologist, it is difficult to predict what form these might take. Because it relates to ethical behaviour, the meaning attached to events and perceptions of the self, moral philosophy and spirituality could add a material dimension to treatments. Moral injury in the absence of PTSD might plausibly be resolved by a priest or an ethicist. The vain hope that governments, institutions and hierarchical bodies in general will seek to promote ethical behaviour is unlikely to be realised, so we may be certain that the phenomenon of moral injury will continue to flourish for the immediate future.

Edgar Jones (D), Professor of the History of Medicine and Psychiatry, Institute of Psychiatry, Psychology and Neuroscience, King's College London, UK

Correspondence: Professor Edgar Jones. Email: edgar.jones@kcl.ac.uk

First received 9 Dec 2019, final revision 8 Jan 2020, accepted 23 Jan 2020

\section{References}

1 American Psychiatric Association. Diagnostic and Statistical Manual of Mental Disorders (5th edn) (DSM-5). American Psychiatric Publishing, 2013.

2 Litz BT, Stein N, Delaney E, Lebowitz L, Nash WP, Silva C, et al. Moral injury and moral repair in war veterans: a preliminary model and intervention strategy. Clin Psychol Rev 2009; 29: 695-706.

3 Steenkamp MM, Litz BT, Hoge CW, Marmar CR. Psychotherapy for military related PTSD: a review of randomized controlled trials. JAMA 2015; 314: 489-500.

4 World Health Organization. ICD-11 for Mortality and Morbidity Statistics (Version: 04/2019). WHO, 2019 (https://icd.who.int/browse11/I-m/en).

5 Shay J. Achilles in Vietnam: Combat Trauma and the Undoing of Character. Scribner, 1994

6 Frankfurt S, Frazier P. A review of research on moral injury in combat veterans. Mil Psychology 2016; 28: 318-30.

7 Williamson V, Stevelink SAM, Greenberg N. Occupational moral injury and mental health: systematic review and meta-analysis. Br J PSychiatry 2018; 212: 339-46. 